\title{
Morphometric and isozyme evidence for the hybrid origin of a new tetraploid radiate groundsel in York, England
}

\author{
JUDITH A. IRWIN \& RICHARD J. ABBOT** \\ Department of Biology \& Preclinical Medicine, Sir Harold Mitchell Büilding, University of St Andrews, St Andrews, Fife \\ KY16 9TH, U.K.
}

\begin{abstract}
A morphometric and isozyme analysis of a fertile tetraploid radiate groundsel discovered in York, England, in 1979, showed it to differ markedly from typical inland radiate groundsel, Senecio vulgaris var. hibernicus. Morphologically, York radiate groundsel was intermediate between $S$. vulgaris and $S$. squalidus plants derived from York and Edinburgh populations. In addition, it exhibited an additive esterase phenotype which combined the $\alpha E s t-1$ and $\beta E s t-1$ phenotypes expressed by $S$. vulgaris and $S$. squalidus, respectively. In contrast, $S$. vulgaris var. hibernicus does not express a $\beta E s t-1$ allozyme. It is concluded that York radiate groundsel is a product of hybridization between $S$. vulgaris and $S$. squalidus quite different from that of $S$. vulgaris var. hibernicus. This new variant appears to be of very recent origin, it exhibits a high level of self seed set, and is currently relatively well established in the city of York. Despite its ability to intercross with typical $S$. vulgaris, it appears to have maintained its distinctive morphological and isozyme phenotype in the wild.
\end{abstract}

Keywords: Compositae, hybrid origin, isozymes, morphometrics, Senecio vulgaris, Senecio squalidus.

\section{Introduction}

The introduction and subsequent spread of the Oxford Ragwort, Senecio squalidus L. $(2 n=20)$, in Britain within the past 300 years (Kent, 1956) has led to the occurrence of two notable evolutionary events following hybridization with the native Groundsel, Senecio vulgaris $\mathrm{L} .(2 n=40)$. The first concerns the origin of the radiate variant of $S$. vulgaris, var. hibernicus Syme, sometime during the early past of the 19th Century (Abbott, et al., 1992a); the second involves the multiple origin of the allohexaploid S. cambrensis $(2 n=60)$, initially in Wales and more recently in Scotland during the present century (Ashton \& Abbott, 1992). There is evidence that the initial step in the origin of each of these new taxa was the formation of the sterile triploid hybrid, $S$. vulgaris $\times S$. squalidus $(2 n=30)$. Ingram et al. (1980) have shown that backcrossing this hybrid to non-radiate $S$. vulgaris (var. vulgaris), followed by selfing, produces fertile radiate offspring bearing a close resemblance to var. hibernicus, while doubling the

*Correspondence. chromosome number of the hybrid creates the fertile $S$. cambrensis (see Rosser, 1955).

In 1979 , a radiate variant of what was considered to be $S$. vulgaris was identified growing together with nonradiate $S$. vulgaris at the edge of a car park in York, England. This variant possessed capitula which were 'showier' than normal for S. vulgaris var. hibernicus, and leaves which were intermediate in shape to those of $S$. vulgaris and $S$. squalidus respectively. All plants of the type were fertile and it was shown subsequently ( $R$. Ingram, personal communication) that their offspring were tetraploid $(2 n=40)$ and formed bivalents at meiosis. It seemed feasible that the York plants could be representative of var. hibernicus, but the products of an independent origin of this taxon in the York area within recent times. Alternatively, the York plants could represent the offspring of a fertile tetraploid hybrid between $S$. vulgaris and $S$. squalidus produced following fusion between a normal gamete of $S$. vulgaris and an unreduced gamete of $S$. squalidus. In this paper we report the results of a morphometric and isozyme comparison of the relevant taxa sampled from York, and also S. vulgaris var. vulgaris, var. hibernicus and $S$. squalidus sampled from a waste site in Edinburgh. We present evidence that the new radiate 


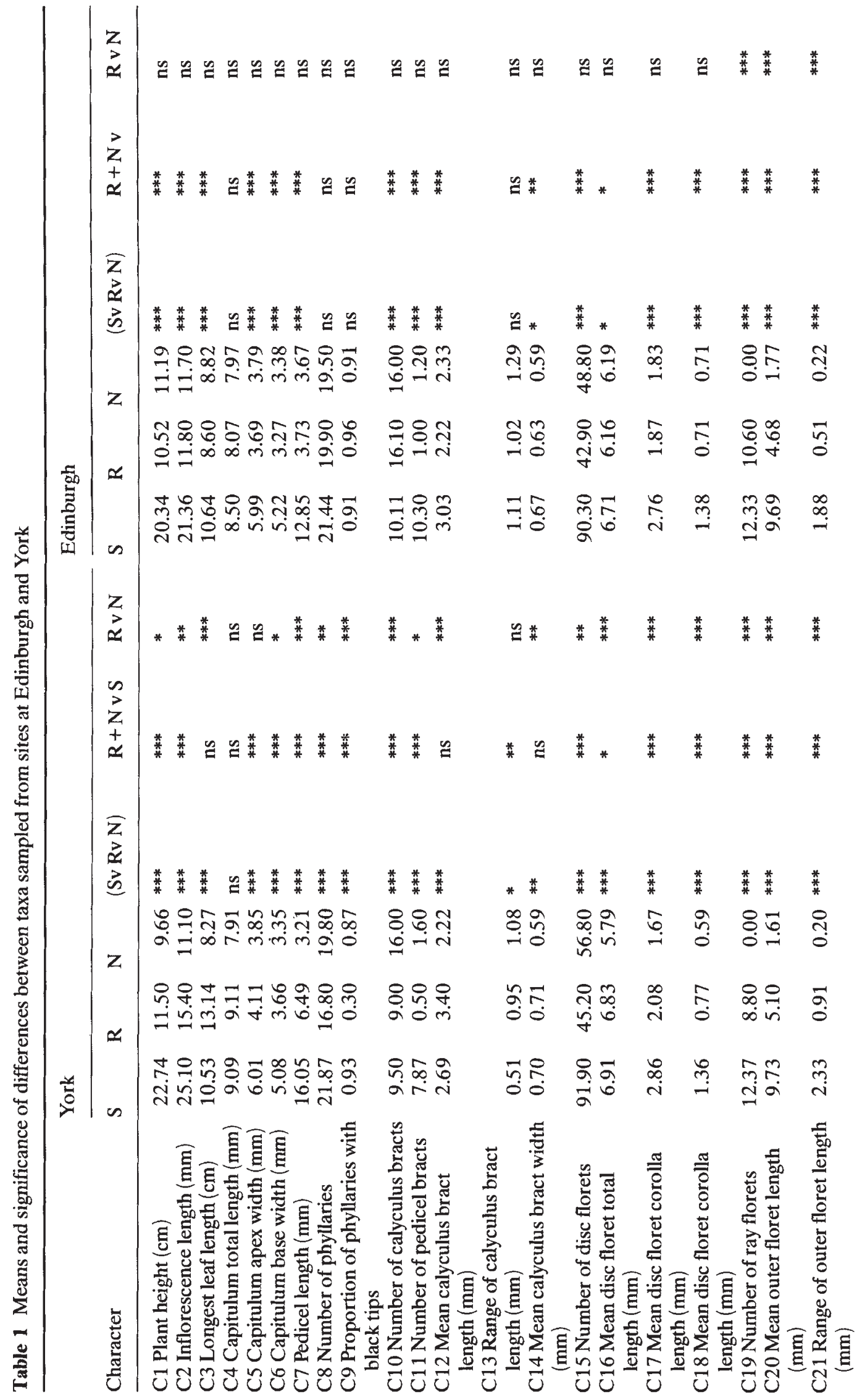


*

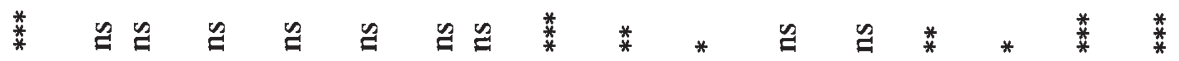

*

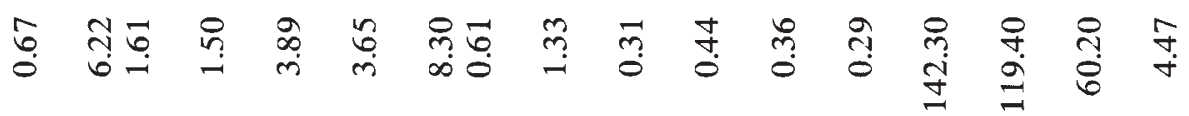

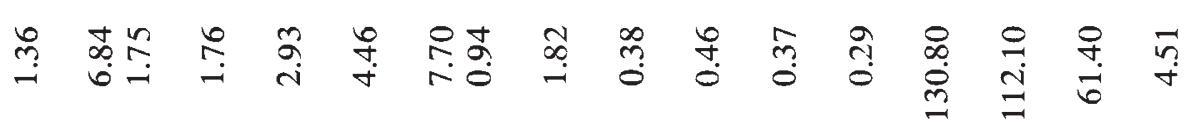
సี * *

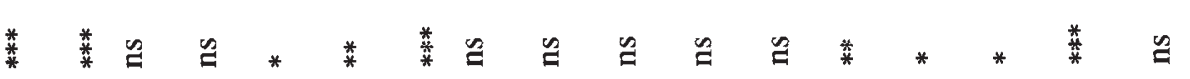

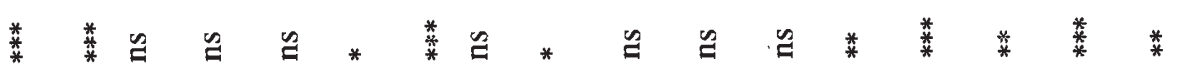

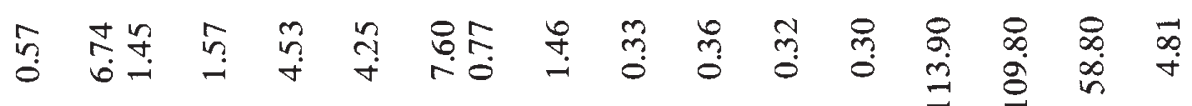

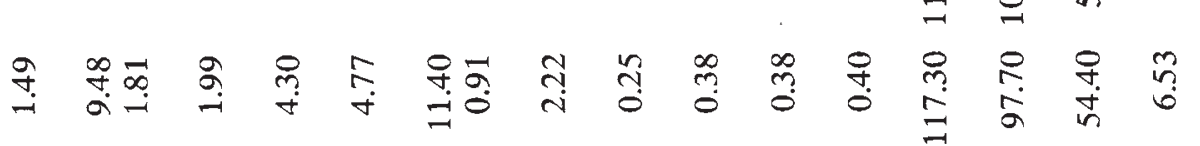
於

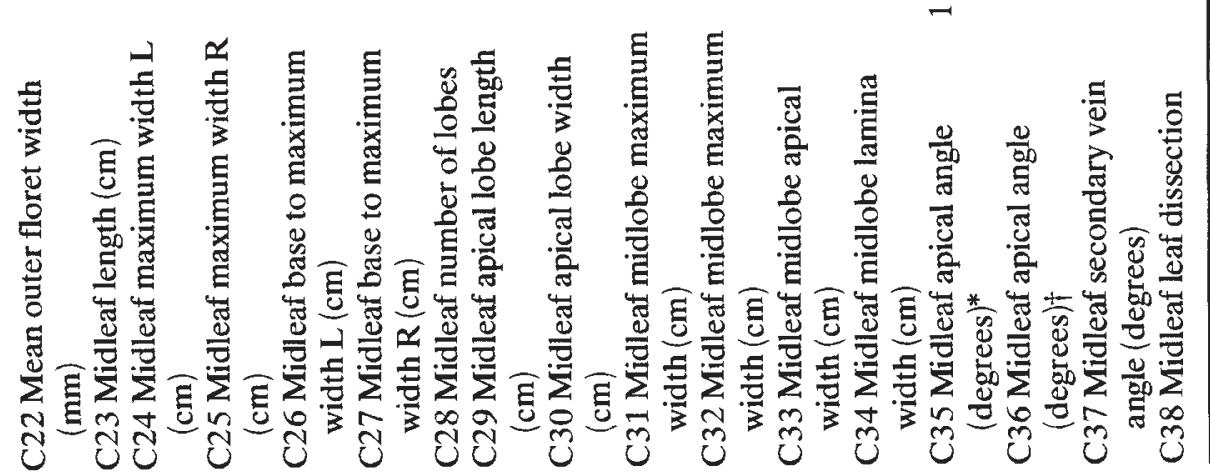

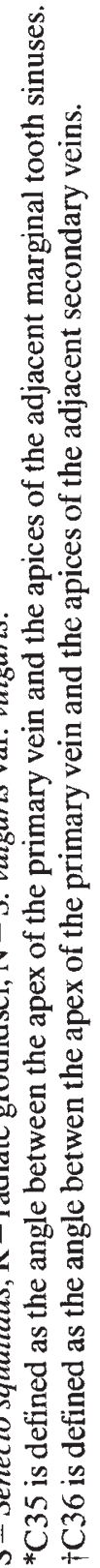


Senecio from York is different in both morphology and esterase phenotype from standard var. hibernicus, and can be considered as a separate product of interspecific hybridization between $S$. vulgaris and $S$. squalidus.

\section{Materials and methods}

\section{Morphometric analysis}

Seed of the unusual radiate groundsel from York (hereafter referred to as York radiate groundsel) and also $S$. vulgaris var. vulgaris was collected from a car park near to York railway station by R. J. Abbott and D. F. Marshall in June 1979. Seed was collected from 20 plants of each taxon and maintained through three generations of selfing before initiating morphometric studies. Seed of $S$. squalidus from the same location in York was collected in June 1988, while seed from samples of each of $S$. squalidus, $S$. vulgaris var. vulgaris and var. hibernicus growing in Edinburgh was collected from waste ground at Salamander Street (Nat. Grid Ref. NT276763) in June 1987.

Seed derived from 10 plants of each taxon from each site was sown on compost contained in 7 -cm pots. Pots were fully randomized within a $6 \times 10$ block on a bench in a glasshouse at the Botanic Gardens, St Andrews. Seedlings were thinned to one per pot at a height of $2-3 \mathrm{~cm}$ and potted on into $11.5 \mathrm{~cm}$ pots at a height of $5 \mathrm{~cm}$. Plants were raised under a $16 \mathrm{~h}$ photoperiod supplied by $400 \mathrm{~W}$ mercury vapour lamps and were harvested individually for measurement on the first full day of anthesis of the apical capitulum.

The character set examined was a reduced form of that measured by Taylor (1984) in a morphometric analysis of members of a polyploid complex of British Senecio. Of the 38 characters that were studied (Table 1 ), half were vegetative, with 16 describing different aspects of the mid-leaf; while the other half were descriptors of the capitulum.

Measurement of characters C1, C2 and C3 (Table 1) was made on fresh material while characters $\mathrm{C} 23-38$ were measured on frozen leaf material. The perimeter of the mid-leaf and its area were measured using a Delta-T area meter (Delta-T Devices, Cambridge) and dissection was estimated as the perimeter divided by the square root of the area, a high ratio indicating a highly divided leaf. Capitulum characters C4-C11, $\mathrm{C} 15$ and $\mathrm{C} 19$ were measured or counted directly, while other capitulum characters $\mathrm{C} 12-\mathrm{C} 14, \mathrm{C} 16-\mathrm{C} 18$ and $\mathrm{C} 20-\mathrm{C} 22$ were measured following placement of material on transparent adhesive tape. A detailed description of the character set is given in Irwin (1990).

Data were initially analysed for each character, in turn, by means of a nested ANOVA to detect differences between taxa, and sites within taxa. The York radiate groundsel, for the purpose of analyses, was considered to be analogous to var. hibernicus. When assumptions of normality and homogeneity of variance were not met, data were transformed into natural logarithms before analysis. Frequently the site within-taxon term was significant (i.e. for 17 of the 38 characters analysed), and so one-way ANOVAs were subsequently conducted on data from within sites. From these ANOVAs orthogonal contrasts were extracted to test for significant differences between the taxa (i.e. var. vulgaris v var. hibernicus, and var. vulgaris and var. hibernicus v. S. squalidus).

Following analysis of variance, the total dataset was subjected to Principal Component Analysis (Manly, 1986) using the statistical package CLUSTAN (Wishart, 1987).

\section{Isozyme analysis}

A survey of isozyme variation was conducted on the material of York and Edinburgh $S$. squalidus, and Edinburgh $S$. vulgaris which had been collected for the morphometric analysis (see above). Isozyme analysis of York $S$. vulgaris var. vulgaris and York radiate groundsel was conducted on material grown from seed collected in June 1991. Seed of York radiate groundsel was collected from two sites: from the river bank by Lendal Bridge (Nat. Grid Ref. SE600519), and from a car park at Dalton Terrace (Nat. Grid Ref. SE594513). Seed of York $S$. vulgaris var. vulgaris was sampled from waste ground approximately $400 \mathrm{~m}$ down river from the Lendal Bridge site. A search conducted at the same time for typical plants of $S$. vulgaris var. hibernicus, resulted in one such individual being found by the railway station approximately $500 \mathrm{~m}$ from the nearest population of York radiate groundsel at Lendal Bridge. This plant was not producing seed at the time of collection and was, therefore, not subjected to further analysis. Isozyme analysis was conducted over the following 11 enzyme systems, on one offspring of each parent plant sampled: acid phosphatase (ACP), aspartate aminotransaminase (AAT), $\alpha$-esterase $(\alpha \mathrm{EST}), \beta$ esterase $(\beta E S T)$, glucose- 6 -phosphate dehydrogenase (G-6-PDH), glyceraldehyde-3-phosphate dehydrogenase (G-3-PD), malate dehydrogenase (MDH), malic enzyme (ME), peroxidase (PER), phosphoglucose isomerase (PGI), phosphoglucomutase (PGM). Details of electrophoretic and staining procedures for these systems are given in Ashton (1990) and Irwin (1990). 


\section{Results}

\section{Morphometric analysis}

Analyses of data from within sites (Table 1) showed that there was significant variation between taxa at each site for the majority of characters measured. However, for Edinburgh material most of the variation was due to differences between $S$. vulgaris and $S$. squalidus with only six characters showing significant differences between the two forms of $S$. vulgaris. In contrast, in York material there was significant variation between S. vulgaris var. vulgaris (non-radiate) and the York radiate groundsel for 25 of the 38 characters examined. Thus, whereas most of the character variation between taxa in Edinburgh material was due to differences between $S$. vulgaris and $S$. squalidus, this was not the case in York material where a significant component of the variation resulted from differences between $S$. vulgaris and the York radiate groundsel.

Principal component analysis (PCA) was conducted after standardizing the data of each character to zero mean and unit standard deviation. From the correlation matrix (Fig. 1), it was evident that capitulum characters tended to be correlated with each other $(\mathrm{C} 4-\mathrm{C} 22)$ as were many of the mid-leaf size characters (C23-C27,
C29-C34). In contrast, there was an absence of correlation between capitulum characters $(\mathrm{C} 4-\mathrm{C} 22)$ and several leaf size characters (C23-C29, C32-C33); however leaf characters which reflected leaf shape (C35-C38) were correlated with most capitulum characters examined.

The eigen values of the first two principal components computed from the correlation matrix accounted for 53.5 per cent of the total variance, with the third component accounting for a further 9 per cent (Table 2). Characters that contributed most to the variation of the first principal component (i.e. exhibited the highest eigen-vector loadings) were: plant height (C1); inflorescence length (C2); longest leaf length (C3); capitulum characters (excluding C8-C9, C13); and the leaf shape characters correlated with capitulum characters (C35-C38). In contrast, characters with high eigen-vector loadings with respect to the second principal component were: longest leaf length (C3); capitulum characters $(\mathrm{C} 8-\mathrm{C} 9, \mathrm{C} 12)$; and mid-leaf characters (C23-C34) other than those correlated with capitulum characters.

A plot of the component values for each plant against the first two principal components (Fig. 2) resolved three distinct groupings among the material examined. Plants of the two taxa of $S$. vulgaris from
Fig. 1 Character correlations significant at $P \leq 0.05$. Key to characters is given in Table 1. (ロ) Significant, ( $\square$ ) non-significant.

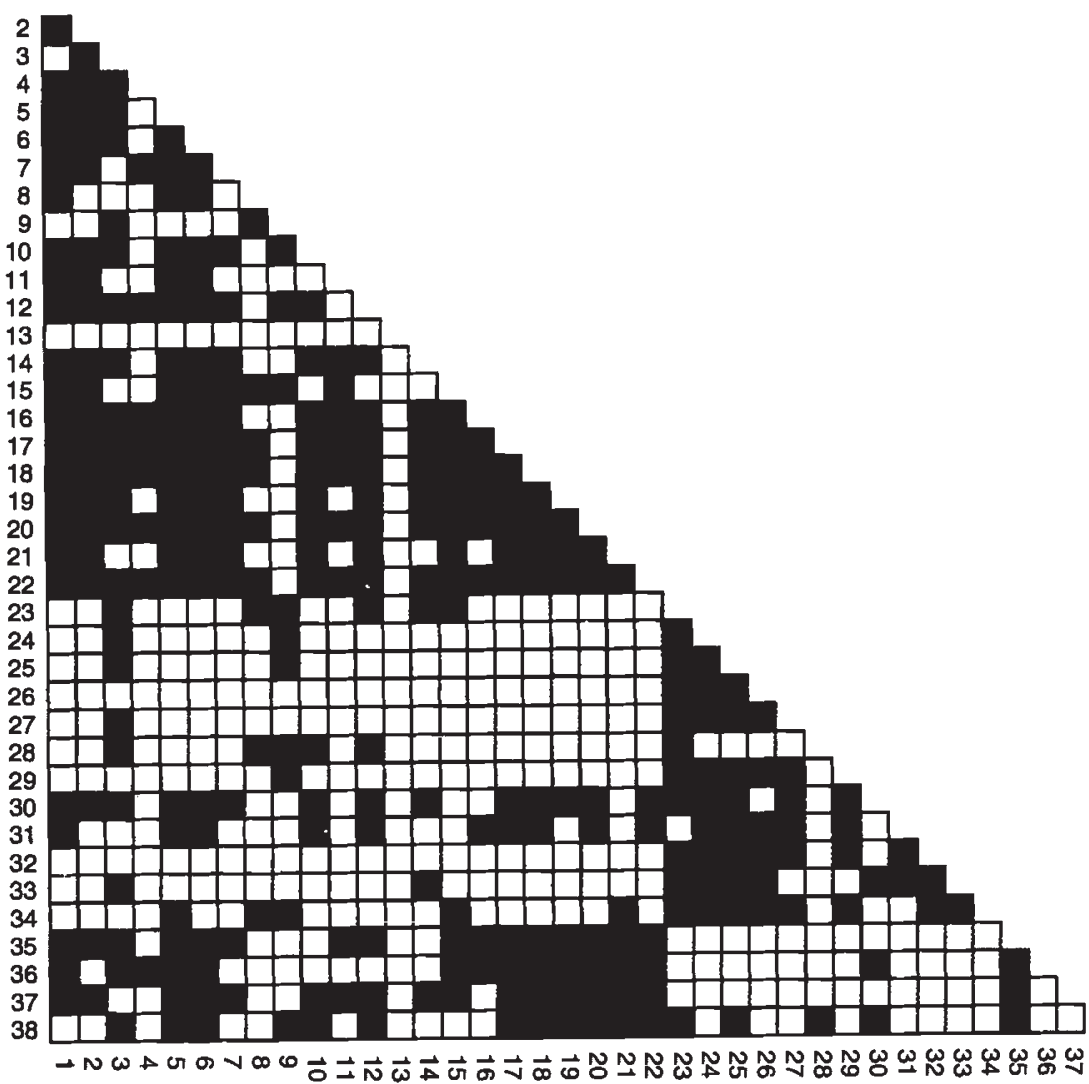


Table 2 Eigen-values (the variance of each principal component), percentage variance and cumulative variance for the first 10 principal components examined

\begin{tabular}{lccl}
\hline Component & Eigen value & $\begin{array}{l}\text { Percentage } \\
\text { variance }\end{array}$ & $\begin{array}{l}\text { Cumulative } \\
\text { variance }\end{array}$ \\
\hline 1 & 13.36 & 35.15 & 35.15 \\
2 & 6.98 & 18.36 & 53.51 \\
3 & 3.42 & 9.00 & 62.51 \\
4 & 1.93 & 5.08 & 67.59 \\
5 & 1.57 & 4.13 & 71.72 \\
6 & 1.45 & 3.83 & 75.55 \\
7 & 1.25 & 3.30 & 78.85 \\
8 & 1.06 & 2.78 & 81.62 \\
9 & 0.94 & 2.48 & 84.10 \\
10 & 0.76 & 2.00 & 86.10 \\
\hline
\end{tabular}

Edinburgh, together with $S$. vulgaris var. vulgaris from York, formed one group, plants of $S$. squalidus from Edinburgh and York formed a second group, while the 10 individuals of the York radiate groundsel formed a third group situated between the other two groups. Note from Fig. 2 that some plants of var. hibernicus from Edinburgh bear a closer morphological resemblance to $S$. squalidus (as might be expected given their introgressive origin) when compared to representatives of var. vulgaris from either site. However, the resemblance of the York radiate groundsel to $S$. squalidus was far more pronounced and indicative of an intermediate hybrid phenotype.

\section{Isozyme analysis}

All taxa surveyed were monomorphic for G-6-PDH, G-3-PD, MDH, ME, PER, PGI and PGM phenotype.
Polymorphism was exhibited for ACP and AAT phenotype (Table 3 ), however the distribution of variation at the two loci of interest, Acp-1 and Aat-3, provided no evidence either for or against the postulated hybrid origin of York radiate groundsel. [A detailed description of phenotype variation at the Acp-1 and Aat-3 loci in $S$. squalidus and $S$. vulgaris, including its genetic basis, is given in Ashton \& Abbott (1992) and Abbott et al. (1992a).] Evidence in favour of a hybrid origin for the York radiate groundsel emerged from the results obtained for esterase variation. Whereas York $S$. vulgaris var. vulgaris and York radiate groundsel were monomorphic for the aEst-1a phenotype, $S$. squalidus failed to express an $\alpha$ Est-1 enzyme. In contrast, $S$. squalidus and York radiate plants were both monomorphic for the $\beta E s t-1 a$ phenotype, while $S$. vulgaris plants (from both sites) showed no $\beta E s t-1$ expression (Fig. 3, Table 3). Previous detailed analysis of esterase variation in $S$. vulgaris and $S$. squalidus (Abbott et al., 1992), has established that whereas $S$. vulgaris var. vulgaris (857 plants tested) and var. hibernicus (594 plants tested) always produce an $\alpha$ Est-1 allozyme, $S$. squalidus never does (822 plants tested). On the other hand, $S$. squalidus always produces the $\beta E$ st-1a allozyme, while $S$. vulgaris does not. The combined expression of both the $\alpha E s t-1$ and $\beta E s t-1$ isozymes by individuals of York radiate groundsel is a clear indication of their hybrid status.

\section{Discussion}

The results of the morphometric and isozyme surveys of variation given here, provide evidence that the tetraploid radiate groundsel, discovered in York by Abbott \& Marshall in 1979, is markedly different from the typical inland radiate form of $S$. vulgaris (var. hibernicus) which was first reported in Britain during the early

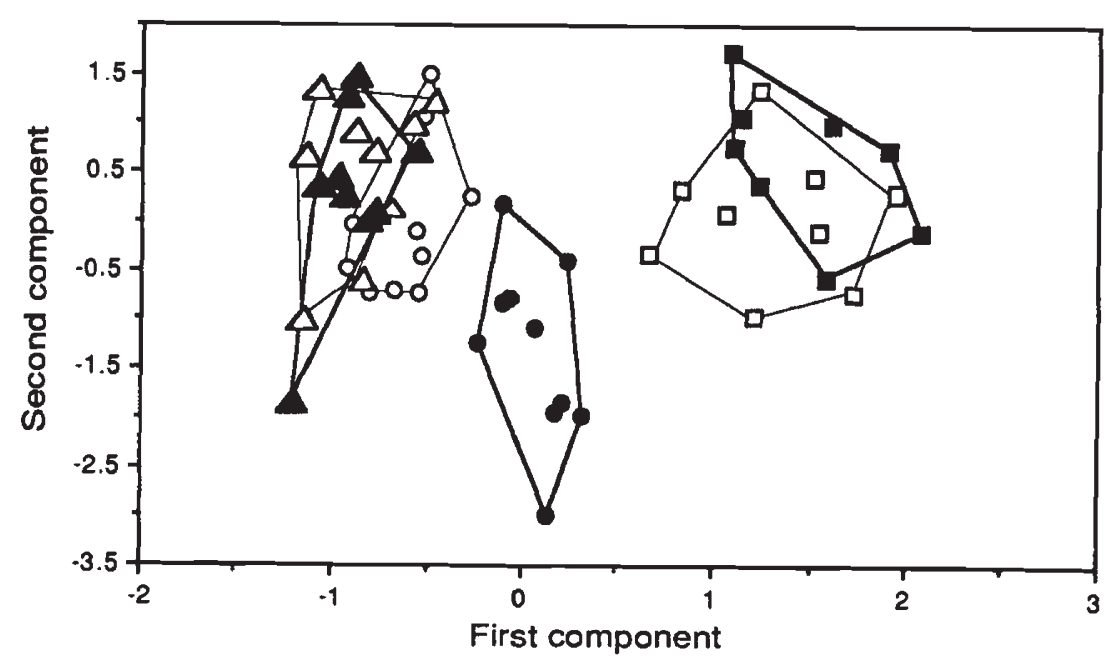

Fig. 2 Plot of the component values for individual plants against the first two principal components. (•) York radiate groundsel, ( $\mathbf{\Delta})$ York $S$, vulgaris var. vulgaris, (-) York S. squalidus, (O) Edin. S. vulgaris var. hibernicus, $(\Delta)$ Edin. S. vulgaris var. vulgaris, (ㅁ) Edin. S. squalidus. 
Table 3 Frequencies of electrophoretic phenotypes for S. squalidus (S), S. vulgaris var. vulgaris $(\mathrm{N})$ and radiate groundsel $(\mathrm{R})$ in populations at Edinburgh and York. (At Edinburgh $(\mathrm{R})$ is $S$. vulgaris var. hibernicus)

\begin{tabular}{|c|c|c|c|c|c|c|}
\hline \multirow[b]{2}{*}{ Locus/phenotype } & \multicolumn{3}{|c|}{ Edinburgh } & \multicolumn{3}{|l|}{ York } \\
\hline & $S$ & $\mathbf{R}$ & $\mathrm{N}$ & $S$ & $\mathbf{R}$ & $\mathbf{N}$ \\
\hline & $n=44$ & 50 & 48 & 26 & 39 & 19 \\
\hline Acp-1a & - & 1.00 & 1.00 & 0.31 & 1.00 & 1.00 \\
\hline$a b$ & - & - & - & 0.31 & - & - \\
\hline$b$ & 1.00 & - & - & 0.38 & - & - \\
\hline$\alpha E s t-1 a$ & - & 0.44 & 0.63 & - & 1.00 & 1.00 \\
\hline$a b$ & - & 0.06 & 0.04 & - & - & - \\
\hline$b$ & - & 0.50 & 0.33 & - & - & - \\
\hline \multirow[t]{2}{*}{$\beta E s t-1 a$} & 1.00 & - & - & 1.00 & 1.00 & - \\
\hline & $n=44$ & 50 & 48 & 35 & 39 & 19 \\
\hline$\beta E s t-3 a b$ & 0.02 & - & - & - & - & - \\
\hline$b b$ & 0.82 & - & 0.22 & 0.97 & - & 0.16 \\
\hline$b c$ & 0.16 & 0.02 & - & 0.03 & - & - \\
\hline \multirow[t]{2}{*}{$c c$} & - & 0.98 & 0.78 & - & 1.00 & 0.84 \\
\hline & $n=44$ & 25 & 27 & 26 & 39 & 19 \\
\hline$A a t-3 a b$ & - & 0.28 & 0.92 & - & 1.00 & 1.00 \\
\hline$a c$ & - & 0.08 & 0.04 & - & - & - \\
\hline$b c$ & 0.25 & 0.64 & 0.04 & 0.50 & - & - \\
\hline$b b$ & 0.02 & - & & 0.15 & - & - \\
\hline$c c$ & 0.73 & - & & 0.35 & - & - \\
\hline
\end{tabular}

$n=$ number of individuals scored.

$\beta E s t 3 b b, 3 b c$ and $3 c c$ in this table are equivalent to the phenotypes. $\beta E s t 3 a, 3 a b$ and $3 b b$ in Ashton \& Abbott (1992).

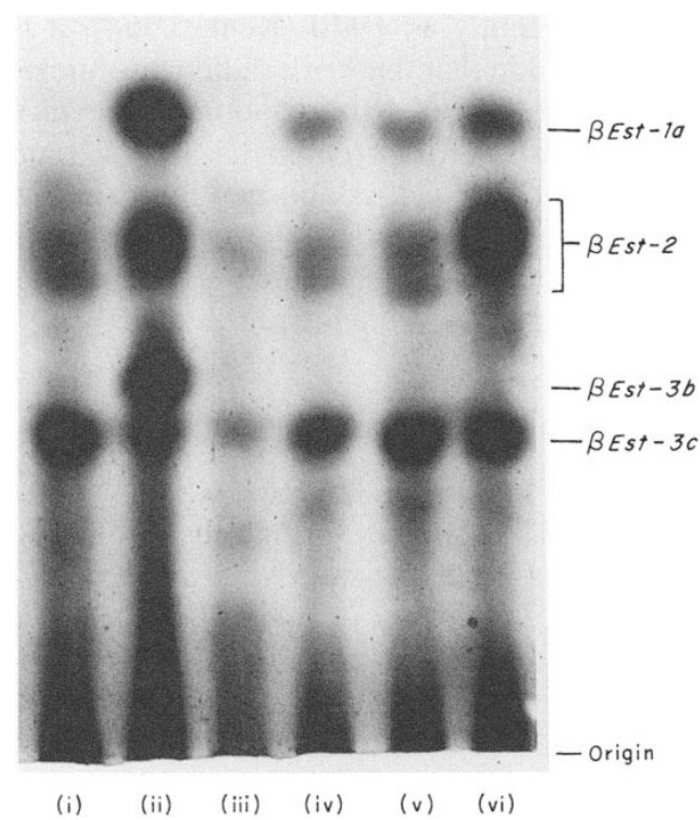

Fig. $3 \beta$-Esterase phenotypes of: (i) $S$. vulgaris var. hibernicus, Edinburgh; (ii) $S$. squalidus, York; (iii) $S$. vulgaris var. vulgaris, York; (iv), (v), (vi) York radiate groundsel. Note the absence of $\beta E s t-1$ expression in (i) and (iii) but the presence of expression in (ii) and (iv)-(vi). part of the 19th Century (Abbott, et al. 1992a). In terms of morphology, the York radiate groundsel exhibits a phenotype which is intermediate between the phenotypes of non-radiate groundsel ( $S$. vulgaris var. vulgaris) and $S$. squalidus plants derived from York populations. In contrast, typical radiate groundsel ( $S$. vulgaris var. hibernicus) produces a phenotype very similar to that of var. vulgaris as evident from the comparison of material derived from an Edinburgh site. The expression of the $\beta E s t-1 a$ isozyme by York radiate groundsel, which is always expressed by British $S$. squalidus plants but never by $S$. vulgaris var. vulgaris or var. hibernicus (Abbott et al. 1992b), together with the expression of the $\alpha E s t-1$ gene, which occurs in $S$. vulgaris but not in $S$. squalidus, provides strong evidence that the York radiate groundsel is a product of hybridization between $S$. vulgaris and $S$. squalidus. It is of interest that all plants surveyed of $S$. cambrensis, the allopolyploid of $S$. vulgaris $\times S$. squalidus, have also been found to express both $\alpha E$ st -1 and $\beta E$ st -1 isozymes (R. J. Abbott personal observation), providing further evidence that the dual expression of these isozymes is a clear sign of hybrid status. In addition to the morphometric and 
electrophoretic differences reported here, previous studies have shown that York radiate groundsel also produces larger seed than either $S$. vulgaris var. vulgaris or var. hibernicus (A'Brook, 1984), and some pollen with four pores (J. A. Irwin personal observation) as well as the three-pore pollen type produced by var. vulgaris, var. hibernicus and $S$. squalidus. The possession of both of these particular characters by individuals of York radiate groundsel may be taken as yet further evidence of their hybrid status in that $S$. cambrensis also produces larger seed than either parent species, and mostly four- rather than three-pore pollen (Rosser, 1955; Abbott et al., 1983).

Although York radiate groundsel can be considered as a product of hybridization between $S$. vulgaris and $S$. squalidus, quite different from that of var. hibernicus, we remain uncertain of its pathway of origin. It is feasible that it too is of introgressive origin, having arisen following backcrossing of the triploid hybrid $(S$. vulgaris $\times S$. squalidus) to $S$. vulgaris. If this is so, the York variant may be an early product of backcrossing with insufficient generations of recurrent backcrossing having taken place to produce the typical var. hibernicus phenotype. Alternatively, it is possible that York radiate groundsel originated as a fertile tetraploid $F_{1}$ hybrid following fusion between a normal gamete of $S$. vulgaris and an unreduced gamete of $S$. squalidus. Taylor (1984) has artifically synthesized such a hybrid between $S$. vulgaris and $S$. squalidus and subjected the material to detailed morphometric analysis. She showed that such hybrid plants produce a morphological phenotype intermediate to those of $S$. vulgaris and $S$. squalidus and, in contrast to the triploid hybrid, are fertile ( 15 per cent self seed set; and up to 70 per cent seed set when backcrossed to $S$. vulgaris var. vulgaris). Evidence against the York radiate groundsel being a direct descendent of a tetraploid $F_{1}$ hybrid comes from the finding that it does not exhibit the expected additive rDNA phenotype of the two parents when its DNA is treated with the restriction enzymes EcoRI, EcoRV and BamH1 (Harris \& Ingram, 1992). However, some plants of the allopolyploid $S$. cambrensis have also failed to produce the expected additive rDNA phenotype when their DNA was treated with the same enzymes, indicating that rDNA phenotype may not always reflect the hybrid status of a plant (see also Zimmer et al., 1988).

Whatever its pathway of origin, the York radiate groundsel appears to have maintained a distinctive morphological phenotype since its discovery in 1979 up until the present time. Moreover, it appears to be electrophoretically monomorphic. Its distinctive phenotype would appear to have been maintained despite the potential for recurrent backcrossing to $S$. vul- garis var. vulgaris in the wild. Such potential is demonstrated by the fact that artificial crosses between $S$. vulgaris var. vulgaris and the York radiate groundsel produce offspring which exhibit high seed fertility (J. A. Irwin personal observation) irrespective of the variant used as the female parent.

At the time of its discovery in 1979, 20 individuals of the York radiate groundsel were recorded over a distance of $10 \mathrm{~m}$ along the edge of a car park in York. When raised in a glasshouse, offspring of 10 of these plants exhibited an equivalent high percentage self seed set per capitulum $(\bar{x}=70.81,95$ per cent $C L= \pm 6.30)$ to that of the offspring of 10 plants of York $S$. vulgaris var. vulgaris collected at the same time $(\bar{x}=70.75,95$ per cent $C L= \pm 6.35$ ). In June 1991, populations of York radiate groundsel, each consisting of more than 200 plants of the variant, were located at two sites $1 \mathrm{~km}$ apart in York. In addition, sporadic plants were found elsewhere in the city. The two populations of the York radiate groundsel were of interest in that they occurred at sites where few individuals of $S$. vulgaris var. vulgaris or var. hibernicus were present. These observations indicate that the York radiate groundsel may occur frequently at sites from which typical $S$. vulgaris plants are largely excluded. If this is so, then this, coupled with the fact that the variant can reproduce by selfing, may help to explain how the distinctive phenotype of York radiate groundsel is maintained in the wild.

Because $S$. squalidus is unlikely to have been present in York until as recently as 1940 (Kent, 1964), it is reasonable to conclude that the York radiate groundsel is a very recent product of hybridization between $S$. squalidus and $S$. vulgaris. Currently this new variant appears to be reasonably well established in the city of York. Its early discovery presents the opportunity to determine which factors may have favoured its establishment and spread during the recent past.

\section{Acknowledgements}

The work was supported by a NERC grant (GR3/6203A) to RJA. We are very grateful to David Forbes and Xia Jing for technical assistance, and also to Terry Crawford, University of York, for his advice and hospitality during a collecting trip to York.

\section{References}

ABBOTT, R. J., ASHTON, P. A. AND FORBES, D. G. 1992a. Introgressive origin of the radiate groundsel, Senecio vulgaris L. var. hibernicus Syme: Aat-3 evidence. Heredity, 68, 425-435.

ABBOTT, R. J., IRWIN, J. A. AND ASHTON, P. A. 1992b, Genetic diversity for esterases in the recently evolved stabilized 
introgressant, Senecio vulgaris L. var. hibernicus Syme, and its parental taxa $S$. vulgaris $\mathrm{L}$. var. vulgaris and $S$. squalidus L. Heredity, 68, 547-556.

ABBOTT, R. J., INGRAM, R. AND NOLTIE, H. J. 1983. Discovery of Senecio cambrensis Rosser in Edinburgh. Watsonia, 14, 407-417.

A'BROOK, R. 1984. Seed weight as a fitness factor counteracting the autoselection of the non-radiate allele in Senecio vulgaris $L$. Honours BSc. Thesis, University of St Andrews.

ASHTON, P. A. 1990. Multiple origins of Senecio cambrensis Rosser, and related evolutionary studies in British Senecio. $\mathrm{PhD}$. Thesis, University of St Andrews.

ASHTON, P. A. AND ABBOTT, R. J. 1992. Multiple origins and genetic diversity in the newly arisen allopolyploid species, Senecio cambrensis Rosser (Compositae). Heredity, 68, 25-32.

HARRIS, S. A. AND INGRAM, R. 1992. Molecular systematics of the genus Senecio L. I: Hybridization in a British polyploid complex. Heredity, 69, 1-10.

INGRAM, R., WEIR, J. AND ABBOTT, R. J. 1980. New evidence concerning the origin of inland radiate groundsel, $S$. vulgaris
L. var. hibernicus Syme. New Phytol, 84, 543-546.

IRWIN, J. A. 1990. Male competition and outcrossing rate in a hermaphrodite plant. PhD Thesis, University of $\mathrm{St}$ Andrews.

KENT, D. H. 1956. Senecio squalidus L. in the British Isles. I. Early records (to 1877). Proc. Bot. Soc. Br. Isles, 2, 115-118.

KENT, D. H. 1964. Senecio squalidus L. in the British Isles. 6. Northern England $(1940 \rightarrow)$. Proc. Bot. Soc. Brit. Is., 5, 217-219.

MANLY, B. J. 1986. Multivariate Statistical Methods, A Primer. Chapman \& Hall.

ROSSER, E. M. 1955. A new British species of Senecio. Watsonia, 39, 228-232.

TAYLOR, L. 1984. The potential for introgression in a British polyploid complex. PhD Thesis, University of St Andrews. WISHART, D. 1987. CLUSTAN: Cluster analysis software. Computing Laboratory, University of St Andrews.

ZIMMER, E. A., JUPE, E. R. AND WALBOT, v. 1988. Ribosomal gene structure, variation and inheritance in maize and its ancestors. Genetics, 120, 1125-1136. 